\title{
Peeling skin syndrome
}

INSERM

\section{Source}

INSERM. (1999). Orphanet: an online rare disease and orphan drug data base. Peeling skin syndrome. ORPHA:817

Peeling skin syndrome (PSS) refers to a group of rare autosomal recessive forms of ichthyosis (see this term) that is characterized clinically by superficial, asymptomatic, spontaneous peeling of the skin and histologically by a shedding of the outer layers of the epidermis. PSS presents with either an acral (acral PSS) or a generalized distribution (generalized PSS type A (non inflammatory) or B (inflammatory)) (see these terms).

Some cases remain difficult to classify, suggesting that there could be additional subtypes of PSS. 